\title{
Immune Response of Eel to Edwardsiella tarda Lipid
}

\author{
Fulvio SALATI and Riichi Kusuda \\ Fish Disease Laboratory, Faculty of Agriculture, \\ Kochi University, Nankoku, Kochi 783, Japan
}

(Received March 14, 1986)

\begin{abstract}
To confirm the properties of the lipid from Edwardsiella tarda as immunosuppressor in the eel, suggested by previous studies, lipid extracted from the whole cell (Lipid), crude lipopolysaccharide (LPS), formalin killed cell (FKC) and whole cell without lipid (CWL) were injected intramuscularly in the eels. To compare the protective effect of the preparations, the eels were challenged with live E. tarda, strain EF-1.

The eels immunized with the Lipid preparation did not show differences in protection against challenge in comparison with the control group, and the highest survival rate was recorded in eels immunized with the crude LPS preparation. The antibody titer of the Lipid immunization group was very low and the highest was in the crude LPS immunization group. In vitro phagocytic activity of the total blood was significantly lower in the Lipid immunization group than that found in the control group, whereas higher activity was shown in the crude LPS immunization group. The phagocytic activity of FKC and CWL immunization groups was not significantly different from that of the control group. The results confirm immunogenic properties of E. tarda lipid as immunosuppressor, which decreases the level of phagocytosis in the eel.
\end{abstract}

Bacterial cells consist of many kinds of immunereactive substances producing a variety of immune responses in the injected animals. To control septicemic disease of eel caused by Edwardsiella tarda, development of a protective vaccine is necessary. Immunization of eel with crude lipopolysaccharide (LPS) or crude polysaccharide from E. tarda produced high antibody titer and immune protection against experimental challenge with E. tarda (SAlati et al., 1984). However it was clear that immune protection and antibody titer were not strictly correlated in the eel infected by $E$. tarda because the titer was lower in the crude polysaccharide immunization group which showed the highest protection. Moreover, previous studies showed that a lipid A preparation, obtained by mild hydrolysis of E. tarda LPS, did not induce protection in the eel (SALATI et al., 1984). Recent studies also showed that a preparation obtained by eliminating the lipid from the whole cells of E. tarda EF-1 induces good protection in the eel (Salati and Kusuda, 1985). From these results, it was suggested that the lipid of E. tarda does not stimulate protective immune response in the eel, but it was not still clear whether the lipid suppressed protective immune response or not.

This study was performed to determine the role of the lipid as immunosuppressor in the eel. To make clear the immunosuppressive properties of $E$. tarda lipid, it is important to know the effect of the lipid on the production of antibody and phagocytosis, in the eel, being possible that this immunosuppression influences the phagocytic activity of the blood. The immunostimulation and/or immunosuppression of the eel's total blood was tested in vitro by counting the phagocytosis activity.

\section{Materials and Methods}

Experimental Animals and Aquaria Ninety to ninety-five gram eel (Anguilla japonica TEMMINCK et SCHLEgel) were obtained from an eel farm in Kochi Prefecture, Japan, and kept at $25^{\circ} \mathrm{C}$ in $60 l$ tanks with recirculating, aerated and filtered well water. The eels were in the tanks a few days before the start of the experiment to accustom them to the new conditions. The fish were not fed during the experiment. 
Microorganism Edwardsiella tarda strain EF-1 was originally isolated in June 1979 from the kidney of diseased eel from Japanese eel ponds in Fukuroi, Shizuoka Prefecture, Japan. The organism was passed into the eel by intramuscular injection to maintain virulence.

Preparation of Antigen Lyophylized EF-1 was precultured in Brain Heart Infusion (BHI, Difco, Detroit, Mi) at $30^{\circ} \mathrm{C}$ for $18 \mathrm{~h}$, then inoculated in the same medium and incubated at $30^{\circ} \mathrm{C}$ for $48 \mathrm{~h}$ with shaking. The broth culture was centrifuged at $10,000 \times g$ for $30 \mathrm{~min}$ and the pellet obtained was washed with distilled water. A portion of the harvested cells was subjected to enzyme digestion and the LPS was extracted by Westphal's phenol-water method as previously described (Salati and Kusuda, 1985). The crude LPS obtained was lyophylized and stored at $5^{\circ} \mathrm{C}$ until used.

Another portion of the harvested cells was resuspended at a concentration of $100 \mathrm{mg} / \mathrm{ml}$ in physiological saline and added with $0.5 \%$ formalin. After a $24 \mathrm{~h}$ incubation, a formalin killed cell suspension (FKC) was obtained.

The vaccine preparation called "whole cell without lipid" (CWL) was obtained extracting the lipid using a modification of the Bligh and Dyer method (KATES, 1972). The pellet obtained was suspended in sterile physiological saline at a concentration of $100 \mathrm{mg} / \mathrm{ml}$ and stored at $5^{\circ} \mathrm{C}$ until used.

The lipid preparation used for immunization of eel was obtained by lyophylization of the lipid extracted from the whole cells as described above.

Immunization of eels The eels were injected intramuscularly with $0.1 \mathrm{ml}$ of $1 \mathrm{mg}$ of crude LPS, $10 \mathrm{mg}$ of FKC preparation, $10 \mathrm{mg}$ of CWL preparation and $1 \mathrm{mg}$ of lipid preparation individually. The fish were reimmunized with the same quantity of antigens 7 days after the first immunization. Control group was injected with $0.1 \mathrm{~m} l$ sterile physiological saline.

Challenge Eels were injected intramuscularly with $0.1 \mathrm{~m} l$ of diluted EF-1 broth culture 25 days after the second immunization. The number of the injected live cells was determined by plate count method. Groups of 20 vaccinated and non-vaccinated eels were challenged with $2.4 \times$ $10^{7}$ cells/fish. Necropsy and reisolation of $E$. tarda EF-1 on TSI Agar (Eiken Chemical Co.,

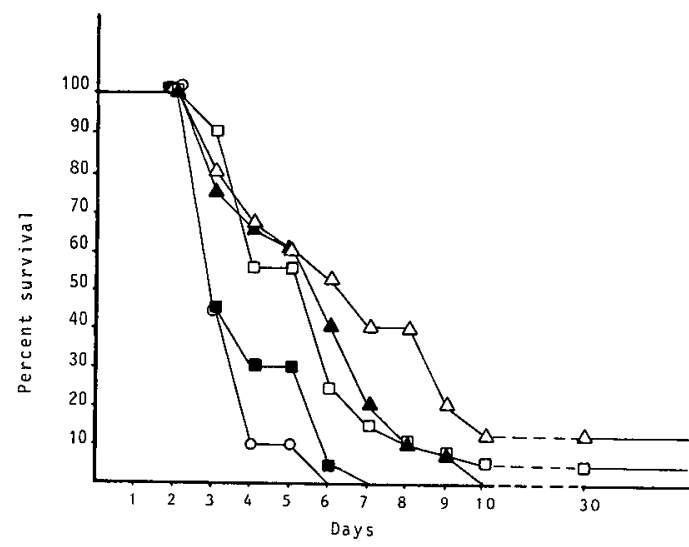

Fig. 1. Survival rate after challenge with $2.4 \times 10^{7}$ cells/fish of Edwardsiella tarda EF-1 in eels immunized with: lipid from whole cells (Lipid: 口), crude lipopolysaccharide (LPS: $\triangle$ ), formalin killed cells (FKC: $\Delta$ ) and whole cells without lipid (CWL: $\square$ ) preparations and controls $(\mathrm{O})$.

\section{Ltd., Tokyo) at $37^{\circ} \mathrm{C}$ were performed.}

Titration of the serum antibody Four eels from each group were bled 21 days after the second immunization to determine agglutination antibody titer against formalin killed whole cells of $E$. tarda EF-1.

Phagocytosis assay Blood was collected from four subjects, each group of healthy vaccinated and unvaccinated eels. One milliliter of total blood was incubated with $50 \mu l$ of formalin killed E. tarda EF-1 $(100 \mathrm{mg} / \mathrm{ml})$ at $25^{\circ} \mathrm{C}$ under shaking. Aliquots of blood were taken at $24 \mathrm{~h}$ of incubation, preparates of the total blood were stained with Giemsa, and the number of phagocytized bacteria was counted in the phagocytic cells.

Immunodiffusion Ouchterlony immunodiffusion of the lipid preparation with rabbit anti-EF-1 serum was performed.

\section{Results}

The results of the experimental challenge are shown in Fig. 1. The eels immunized with the lipid preparation resulted the lowest in survival rate among the immunized groups and did not show differences in protection to the control group. A higher protection was obtained by immunization with crude LPS and CWL pre- 
Table 1. Antibody titer in eel immunized with lipid from whole cells (Lipid), crude lipopolysaccharide (LPS), formalin killed cells (FKC) and whole cells without lipid (CWL) from Edwardsiella tarda

\begin{tabular}{|c|c|}
\hline $\begin{array}{l}\text { Immunization } \\
\text { group }\end{array}$ & $\begin{array}{l}\text { Agglutination } \\
\text { titer (1:) }\end{array}$ \\
\hline Lipid & $\begin{array}{r}16 \\
16 \\
16 \\
8\end{array}$ \\
\hline LPS & $\begin{array}{l}2,048 \\
1,024 \\
1,024 \\
1,024\end{array}(1,218)$ \\
\hline FKC & $\begin{array}{r}2,048 \\
1,024 \\
1,024 \\
512\end{array}(1,024)$ \\
\hline CWL & $\begin{array}{l}512 \\
512 \\
512 \\
256\end{array}\left(\begin{array}{l} \\
251)\end{array}\right.$ \\
\hline Control & $\begin{array}{l}8 \\
8 \\
8 \\
4\end{array}$ \\
\hline
\end{tabular}

* Figures in parentheses indicate geometric mean of titer.

parations. However, the difference in protection of these immunization groups and control group was statistically insignificant.

The agglutination antibody titer recorded in the vaccinated and unvaccinated eels is shown in Table 1. Very low antibody titer was shown in the eels immunized with the lipid preparation in comparison to the other immunization groups. The lipid was not effective in rising the antibody titer. The highest antibody titer was shown in the crude LPS immunization group, followed by the FKC and the CWL immunization groups.

The results of the in vitro counting of the total blood phagocytosis activity are shown in Table 2 . The average percent of the cells showing phagocytic activity (PA) was significantly different between the lipid immunization group $(P \leqq 0.01)$ and control subjects and between the control group and crude LPS immunization group ( $P \leqq$ 0.01 ), but was not significant among the control
Table 2. In vitro Phagocytosis Activity (PA) and Phagocytic Index (PI) of total blood from eels immunized with Edwardsiella tarda lipid, crude lipopolysaccharide (LPS), formalin killed cells (FKC) and whole cells without lipid (CWL) preparations

\begin{tabular}{lll}
\hline \hline $\begin{array}{c}\text { Immunization } \\
\text { group }\end{array}$ & PA*1 & PI*2 \\
\hline Lipid & $10.5( \pm 4.9)$ & $2.0( \pm 0.7)^{* 3}$ \\
LPS & $74.5( \pm 3.8)$ & $8.7( \pm 2.1)$ \\
FKC & $55.5( \pm 11.5)$ & $4.4( \pm 1.9)$ \\
CWL & $39.0( \pm 6.7)$ & $3.6( \pm 2.9)$ \\
Control & $43.5( \pm 6.5)$ & $8.7( \pm 1.9)$ \\
\hline$* 1$ & PA=Phagocytosis Activity: & percent of cells \\
*2 & PI=Phing phagocytic activity. \\
gested/phagocyte in a 24 h incubation period. \\
Figures in parentheses indicate the Standard \\
Deviation.
\end{tabular}

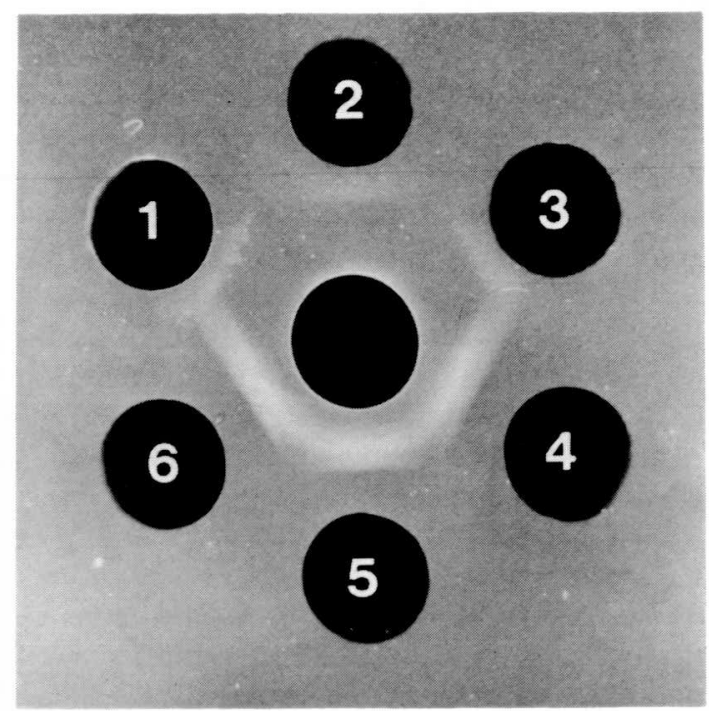

Fig. 2. Ouchterlony immunodiffusion analysis of lipid from whole cells (Lipid) and crude lipopolysaccharide (LPS) of Edwardsiella tarda EF-1. Peripheral wells: 1, 2 and 3, Lipid; 4, 5 and 6, crude LPS. Central well: anti-EF-1 serum.

group, CWL and FKC immunization groups. The average number of bacteria phagocytized per one hundred leukocytes (PI) decrease specifically only in the eel immunized with lipid extracted from E. tarda EF-1 cells when compared to the 
control group's PI.

Ouchterlony immunodiffusion of the lipid preparation used for immunization of eels is shown in Fig. 2. The lipid preparation showed one precipitin line which was not identical to the crude LPS precipitin line because a spur was observed.

\section{Discussion}

Bacterial lipids generally possess a strong anticomplement activity in mammals (CLERICI and VILLA, 1978a), but there is no available data about their immunological activity in the eel. A previous study on eel showed that the elimination of the lipid from E. tarda EF-1 whole cells gave good protection to experimental challenge (SAlati and Kusuda, 1985). This result suggested that the lipid of E. tarda does not stimulate protective immune response in the eel. This experiment was performed to confirm whether or not the lipid extracted from whole cells of $E$. tarda EF-1 had immune suppressive properties.

The results of the experimental challenge of the eels immunized with E. tarda EF-1 lipid did not show higher protection rate than the control group. For the strength of the challenge, which was rather strong, more than the EF-1 strain's lethal dose established for the eel by KUSUDA and IsHiHara (1981) to be of $1 \times 10^{6.8}$ cells, the crude LPS immunization failed to protect the eels significantly. The results of agglutination test also showed insufficient antibody titer in the eels immunized with the lipid preparation as low as the control group. Instead of low immunogenicity of the lipid preparation used for immunization of the eels, repeated immunodiffusion analysis showed that the lipid produced one precipitin line using anti-EF-1 rabbit serum. It is not clear but this suggests that the lipid of $E$. tarda reacts as antigen with antigenicity not correlated with immunogenicity in the eel.

The high antibody titer showed in the crude LPS and FKC immunization groups confirms the results of previous studies (SAlATI et al., 1983, 1984), but the titer recorded for the CWL immunization group was lower than that obtained in the preceding study (SALATI and KusUdA, 1985). The relatively low titer could be explained, besides being conditioned by the hetero- geneity of the eels, by differences in immunogenicity of the preparations used because the extraction of the lipid was carried out using different methods. In vitro phagocytosis activity (PA) of the total blood from the immunized and unimmunized eels showed a significant difference between the lipid immunization group and the control group where the PA of the lipid immunization group was very low: less than one-fourth of the controls. Low activity was also shown in the lipid immunization group's average number of bacteria phagocytized per one hundred leukocytes (PI): less than one-fourth of the controls PI.

Lipopolysaccharide is a direct stimulator of murine B cell lymphocytes (NORIN and SHORT, 1982) and increases the phagocytic activity of mammal's leukocytes (CLERICI and VILLA, 1978b). In this experiment, while the crude LPS immunization group did not show significant protection to the strong experimental infection, the results of the in vitro phagocytosis assay showed that the PA was significantly different when compared to the control group. This confirms the capacity of the crude LPS to enhance the phagocytic activity of the eel's leukocytes and also increases serum antibody titer which together may protect the eel to the natural infection by E. tarda.

There are a few studies on phagocytosis and immune response of the eel to E. tarda whole cells (Song and Kou, 1981; Mushiake et al., 1985), but there is no data about bacterial lipid. Results of a previous study indirectly suggested that the eel's protective immune response would not be stimulated by E. tarda lipid (SALATI and KusUdA, 1985). Results of this study are summarized as follows: the lipid extracted from whole cells of $E$. tarda EF-1 does not induce immune protection in the eel to experimental challenge; it produces a very low agglutination antibody titer in the injected eel; it reduces significantly the in vitro phagocytosis activity of the eel total blood. Particularly, the significant reduction of the phagocytosis activity shows an immunological activity of the lipid, not only as hapten. From these results it is possible to assume that the lipid of E. tarda EF-1 acts as immunosuppressor in the eel. 


\section{References}

ClericI, E. and M. L. ViIla (1978a): Immunologia generale. Ed. UTET, Torino, 49-50.

Clerici, E. and M. L. Villa (1978b): Immunologia generale. Ed. UTET, Torino, 393-433.

KATES, M. (1972): Techniques of lipidology. By T. S. WORK and E. WORK: "Laboratory techniques in biochemistry and molecular biology", North Holland Publishing Company, Amsterdam, 351.

KUSUDA and IsHiHARA (1981): The fate of Edwardsiella tarda bacteria after intramuscular injection of eels, Anguilla japonica. Bull. Japan. Soc. Sci. Fish., 47(4), 475-479. (in Japanese).

Mushiake, K., T. NaKaI and K. Muroga (1985): Lowered phagocytosis in the blood of eels exposed to copper. Fish Path., 20(1), 49-53. (in Japanese). Norin, A. J. and M. K. SHORT (1982): Replicative properties of lipopolysaccharide-induced murine B lymphocytes: detection of three different responses to mitogenic restimulation. J. Immunol., 129(6), 2377-2381.

Salati, F., K. Kawai and R. Kusuda (1983): Immuno-response of eel against Edwardsiella tarda antigens. Fish Path., 18(3), 135-141.

Salati, F., K. Kawai and R. Kusuda (1984): Immune response of eel to Edwardsiella tarda lipopolysaccharide. Fish Path., 19(3), 187-192.

Salati, F. and R. Kusuda (1985): Vaccine preparations used for immunization of eel Anguilla japonica against Edwardsiella tarda infection. Bull. Japan. Soc. Sci. Fish., 51(8), 1233-1237.

Song, Y. L. and G. H. Kou (1981): The immunoresponse of eel (Anguilla japonica) against Edwardsiella anguillimortifera as studied by the immersion method. Fish Path., 15(3/4), 249-255. 